\title{
The landscape epidemiology of foot-and-mouth disease in South Africa: A spatially explicit multi-agent simulation
}

\author{
Elise Dion ${ }^{\mathrm{a}, *}$, Louis VanSchalkwyk ${ }^{\mathrm{b}}$, Eric F. Lambin ${ }^{\mathrm{a}, \mathrm{c}}$ \\ a Georges Lemaître Centre for Earth and Climate Research, Earth and Life Institue, Université catholique de Louvain, Belgium \\ ${ }^{\mathrm{b}}$ Centre for Veterinary Wildlife Studies, Faculty of Veterinary Science, University of Pretoria, South Africa \\ ' School of Earth Sciences and Woods Institute, Stanford University, Stanford, CA, United States
}

\section{A R T I C L E I N F O}

\section{Article history:}

Received 7 December 2010

Received in revised form 8 March 2011

Accepted 17 March 2011

Available online xxx

\section{Keywords:}

Multi-agent simulations

Spatial epidemiology

Foot-and-mouth disease

Wildlife-livestock interactions

Protected area

\begin{abstract}
A B S T R A C T
This study aimed at understanding how landscape heterogeneity influences outbreaks of contagious diseases in southern Africa. Landscape attributes influence patterns of movement and behaviour of animal hosts, virus spread and survival, as well as land use practices. A multi-agent simulation was developed to represent the spatial and temporal dynamics of pathogens between human-livestock and wildlife interfaces at the fringe of large wildlife conservation areas. The model represents the three main elements associated with epidemics - populations, space, and time - to simulate direct contacts between wildlife and livestock. The dynamics of these populations emerge from interactions between agents and the landscape. The model was calibrated to represent the transmission of foot-and-mouth disease through direct contact at the border of the Kruger National Park in South Africa. In the region, African buffaloes (Syncerus caffer) act as reservoirs of the virus and spread the infection to domestic cattle bordering the park. We tested the sensitivity of various factors influencing contact rate between buffaloes and cattle, and thus the risk of foot-and-mouth disease transmission. Results show that cattle-buffalo contacts mostly depend on the range of displacements of cattle and buffaloes, as influenced by the landscape configuration, and on the number of fence breakages multiplied by the time between breakage and repair. Contacts take place not only close to water-points but also in grazing areas, within an area up to $6 \mathrm{~km}$ from the fence.
\end{abstract}

(ㄷ) 2011 Elsevier B.V. All rights reserved.

\section{Introduction}

Spatial (or landscape) epidemiology is the study of spatial variations in disease risk and the analysis of the impact of landscape structures on epidemiological processes (Ostfeld et al., 2005). Infectious disease transmission emerges from interactions, albeit directly or indirectly, between infective and susceptible hosts. As these interactions take place in a geographical space, the consideration of spatial attributes is important to understand the dynamics of infectious diseases (Lambin et al., 2010; Ménard, 2002). Parts of the variations in disease risk can be explained by landscape heterogeneity, environmental changes, and climatic conditions (Kitron, 1998; Ostfeld et al., 2005). Understanding the influence of landscape patterns on risk factors is a prerequisite for efficient control of diseases.

Foot-and-mouth disease (FMD) is a viral disease from the family picornoviridae that is highly contagious (Sutmoller et al., 2003;

\footnotetext{
* Corresponding author at: Place Louis Pasteur 3, 1348 Louvain-la-Neuve, Belgium.

E-mail address: elise.dion@uclouvain.be (E. Dion).
}

Thomson and Bastos, 2004). It is one of the most important livestock diseases in the world. It has the potential to infect all clovenhoofed animals (wildlife, cattle, goats, sheep, pigs) as well as camelids and has major economic impacts on animal trade (Keeling et al., 2001; Thomson and Bastos, 2004). The disease is mostly transmitted via direct contact between infected and susceptible animals (Alexandersen et al., 2003), with the possibility of multiple infections with various serotypes. In some cases, the infection is transmitted through indirect contact - e.g., it can spread through the environment or mechanically by persons, vehicles, wild animals, or birds (Sutmoller et al., 2003).

FMD is endemic to southern Africa (Klein, 2009; Vosloo et al., 2002). In this region, African buffaloes (Syncerus caffer) can become persistently infected with FMD virus without any apparent clinical disease signs, and are generally responsible for outbreaks in cattle (Kitching, 2005). Along the boundaries of nature reserves endemically infected with FMD, African buffaloes and domestic cattle come into contact at shared water points and grazing areas, often resulting in FMD outbreaks in domestic cattle. In the recent past, several such outbreaks have taken place around the Kruger National Park (KNP), a large wildlife conservation area situated in the northeastern corner of South Africa (Brückner et al., 2002). To 


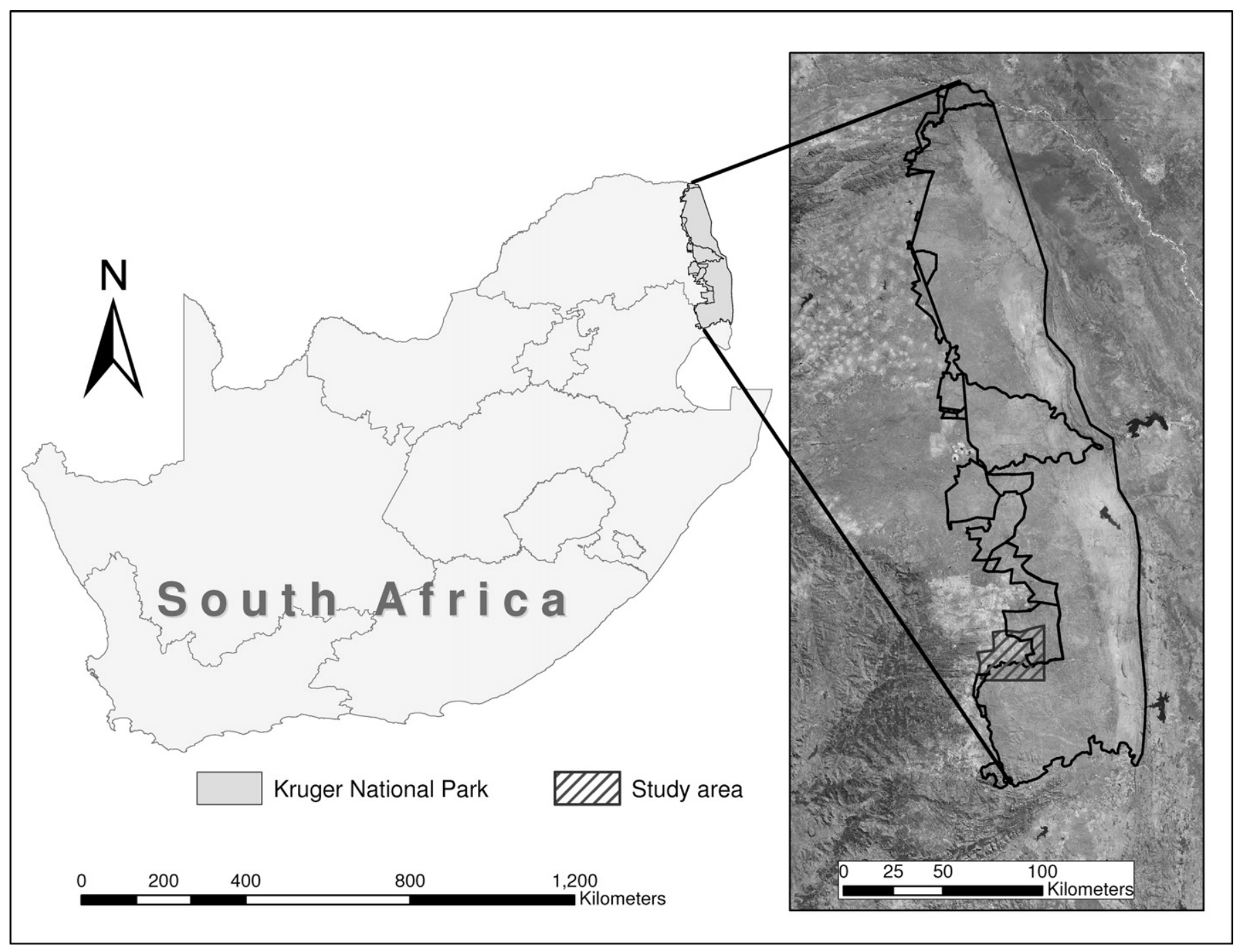

Fig. 1. Study site bordering the Kruger National Park.

better understand the role of landscape patterns on FMD transmission at the wildlife-livestock interface, we developed a spatially explicit multi-agent simulation (MAS) for a study site adjoining the KNP to the west, spanning an area of approximately $2000 \mathrm{~km}^{2}$ (Fig. 1).

Several spatial models were developed for FMD in non-endemic regions such as Europe, USA, and Australia (Bates et al., 2003; Diggle, 2006; Ferguson et al., 2001; Gerbier et al., 2002; Keeling et al., 2001; Lawson and Zhou, 2005; Morris et al., 2001; Rivas et al., 2004). None so far was developed for FMD endemic regions such as southern where transmission risk is different compared to non-endemic regions. Only no spatial models on risk assessment have been developed in such area (Sutmoller et al., 2000; Jori et al., 2009). In endemic regions, the transmission occurs mainly through direct contact between wildlife and domestic animals while, in nonendemic areas, transmission occurs mainly from farm to farm, after a focal introduction of the virus in the area (Kitching, 2005). Pigs excrete the virus in large quantities, which can facilitate airborne spread over considerable distances (Donaldson and Alexandersen, 2002). However, a relatively low density of pigs and a climate less suitable to virus survival outside the host create a very different transmission risk scenario in southern Africa compared to Europe (Thomson and Bastos, 2004).

Our MAS represents interactions between landscape attributes, wildlife and livestock in a bottom-up approach. A MAS is a simu- lation tool representing interactions between multiple agents in a spatially explicit environment. A MAS is defined by: (i) agents, or groups of autonomous individuals, with similar characteristics, that are moving, interacting and communicating in an environment; (ii) an environment, represented by georeferenced land cover attributes; and (iii) decision rules that specify the behaviour of agents and the relationships between them at a micro level (Ferber, 1995). In our model, the basic units, or lower-level elements (i.e., the only programmed elements of the model), are individuals and landscape patches. Higher-level elements - emergent behaviours and patterns such as an FMD outbreak - result from interactions between the actions of lower-level entities (Grimm et al., 2005; Parrott, 2009). A MAS splits processes into many components, thus relying on empirical studies and an extensive literature review to parameterise the decision rules (Kostova et al., 2004). MASs have seldom been used to study the epidemiology of infectious diseases, with notable exceptions however (Bonnell et al., 2010; Linard et al., 2009; Perez and Dragicevic, 2009; Roche et al., 2008). The subtle interplay of causes and effects, and the presence of feedbacks in MASs, allow exploration of the mechanisms driving disease dynamics better than with classical continuous (differential equations) and discrete (discrete-time equations) dynamics system models (Bithell et al., 2008).

We developed an object-based model, named EPIFMD (EPIdemiology of FMD) to address the following question: how do landscape 


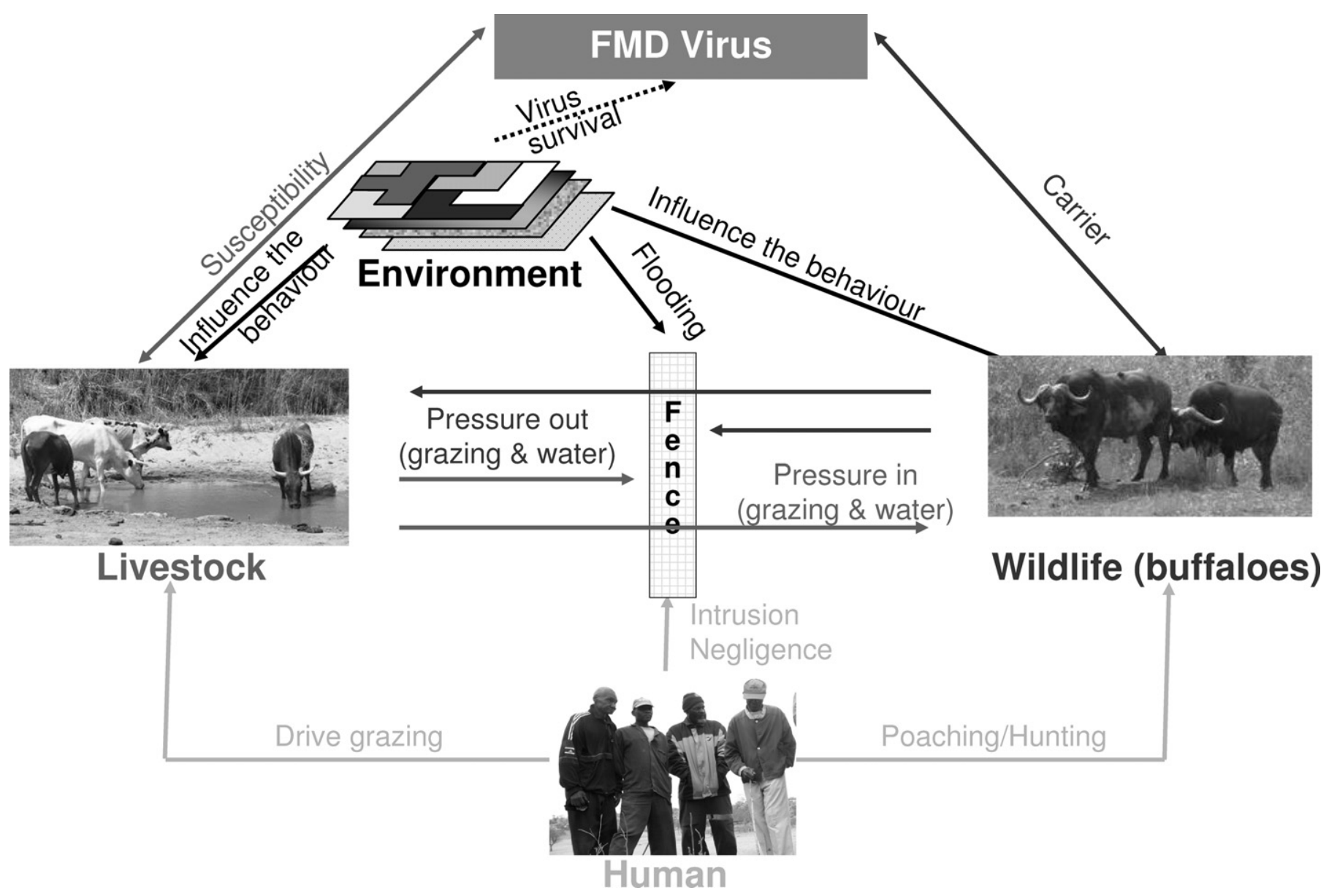

Fig. 2. Processes of FMD transmission near large conservation areas in southern Africa.

patterns and their changes influence the epidemiology of footand-mouth disease at the fringe of conservation areas in southern Africa? The objective of this study was to develop a "virtual laboratory" to allow testing of hypotheses inspired by various scenarios related to the FMD transmission cycle. This paper describes the EPIFMD model and its implementation for an FMD-endemic region in southern Africa. Below, the model presentation follows the standard protocol (Overview, Design concepts and Details - ODD) (Grimm et al., 2006) generally used to describe MAS. We then discuss the verification of the model.

\section{Transmission cycle of foot-and-mouth disease in South Africa}

The epidemiology of FMD in Africa is more complicated than in other parts of the world. Seven FMD serotypes are recognised worldwide, of which three are endemic to certain areas in southern Africa (Southern African Territories (SAT) serotypes 1, 2 and 3) (Kitching, 2005). Within KNP, the African buffalo is the main reservoir of FMD (Kock, 2005). One herd can be permanently infected without developing clinical disease and act as reservoir for future transmission of the virus (Sutmoller et al., 2003). A buffalo can be the carrier of the virus for up to five years (Vosloo et al., 2002). Buffalo calves play an important role in the dynamics of the disease, because they are the most infectious individuals (Gainaru et al., 1986). They become susceptible to FMD in the period after their maternal antibodies wane and before their natural immunity develop, which coincides with the age three to eight months (Bastos et al., 2000; Vosloo et al., 2007). The maintenance of FMD by wildlife makes the eradication of the virus impossible without the destruction of large numbers of African buffaloes - a solution that is both ecologically and morally untenable (Thomson et al., 2003a).

Traditional livestock management systems prevail in most of the area neighbouring KNP, with communal herds being herded by agro-pastoralists daily between "kraals" (a local term for an enclosure for livestock located within a village) (Düvel and Afful, 1996), grazing and drinking areas. To limit transmission risk to cattle living around KNP, cattle herds are vaccinated twice per year and inspected for any signs of clinical FMD once per week by the para-veterinary personnel of the government veterinary services (Brückner et al., 2002; Thomson, 2008; Vosloo et al., 2002). A fence was erected around the KNP in an attempt to prevent domestic cattle coming into contact with buffaloes in the late 1960s (Brückner et al., 2002; Sutmoller et al., 2000; Sutmoller, 2002; Thomson, 1996; Thomson et al., 2003a). Despite these measures, the risk of disease spread to domestic cattle is still present (Vosloo et al., 2002). The efficacy of the vaccine varies by serotype and never reaches $100 \%$ (Thomson et al., 2003b). The fence is permeable as a result of direct and/or indirect impacts of various physical or eco-climatic factors (Taylor and Martin, 1987): it is frequently destroyed by floods, erosion, elephants, or people (mostly poachers, wood collectors, and vandalists). Fence breakages enable buffaloes to come into direct contact with domestic cattle, thus increasing the risk of FMD transmission (Fig. 2).

South African parks are famous for their ecological diversity and touristic value. Domestic cattle play a major role in the livelihoods of the "communal farmers" located around the KNP, despite 
a low productivity per head of cattle and a low commercial value of livestock in these areas (Barrett, 1992; Düvel and Afful, 1996). Understanding land use dynamics associated with disease risk is important to better manage the buffer areas around these natural reserves.

\section{Data}

\subsection{Remote sensing and GIS data}

Remote sensing imagery was used to map environmental attributes of the study area. A land cover map was derived from a SPOT $4,10 \mathrm{~m}$ fusion image of its multispectral and panchromatic bands from August 11th, 2008. We used a classification approach combining: (i) a tree classification method for land use features and water classes, and (ii) a supervised maximum likelihood classification including a spatial texture metric for natural vegetation cover classes. Seven land cover categories were identified: settlements, croplands, water, bare soils, open sparse bush lands, open wood bush lands, bush thickets. Land cover classes were based on the standard land cover classification scheme for remote sensing applications in South Africa (Thompson, 1996). An NDVI time series derived from SPOT Vegetation imagery for a period of 20 years, from 1986 to 2006 (Swinnen and Veroustraete, 2008) was used to extract the annual variability and seasonal evolution of biomass. An accessibility map was created using GIS analysis. It combines distances to roads (1:50 000 map layers, Surveyor General, South Africa) weighted by population density data (Census 2001, Statistics South Africa). All GIS layers were georeferenced to Universal Transverse Mercator (UTM) WGS84 (zone 36S).

\subsection{Field data}

\subsubsection{Field work}

Field observations associated with GPS points were collected to train and validate the land cover classification and the water model during a field trip in September 2008. Approximately 400 GPS points were collected: 200 for training and 200 for validation. A semi-random sampling methodology was used: observations were mostly made at randomly selected locations at short distances from roads, as the dense vegetation makes the landscape quite inaccessible. The accuracy of the land cover classification was evaluated by a Kappa index of agreement, whose value of 0.7 indicated an acceptable classification accuracy.

During the field trip, 120 water points (rivers, dams and water streams) were sampled and information relating to the nature of each water point was recorded: presence or absence of water, main land cover of riverbeds and banks, water characteristics (Fostier, 2009). All water points situated close to roads were selected. These points were used to validate the output of the hydrographical submodel of EPIFMD.

\subsubsection{Key informants}

To better grasp the complexity of the system, we conducted discussions with several key informants: specialists from the State Veterinary Services, members of South African National Parks (SANParks), and local community members. Topics covered included animal diseases; rural organisation; cattle, wildlife and park management practices. A few meetings were also organised with local experts in FMD risk factors.

\subsubsection{Socio-economic surveys}

Socio-economic surveys were conducted in the study area in 2008 based on a questionnaire. The goals were to understand the social organisation of local villages, to collect data on the socioeconomic status of herdsmen and their decision-making rationale, and to estimate the risk of FMD transmission. Forty cattle owners were interviewed at government veterinary inspection points, which are visited by herdsmen with their cattle once a week. This survey revealed, for instance, that the main activities of herdsmen in the study area are cultivation and cattle herding, and that these local herdsmen are more concerned by water and grazing availability than by FMD.

\subsubsection{Cattle information and cattle tracking}

Monthly livestock register reports by government animal health technicians from 2003 to 2007 were collected in hard copy from the local State Veterinary Office. These included data on animal numbers, births, mortalities, sales and slaughter.

To better understand cattle grazing patterns, a cattle grazing study utilizing handheld GPS units was conducted between May 2008 and September 2009 (unpublished data, Van Schalkwyk et al.). In communal farming systems, groups of cattle are generally herded by a paid herdsman or by the cattle owner. In the study area, 24 herdsmen from 7 inspection points (3-6 per inspection point) were selected through a stratified sampling design based on the location of the inspection point in relation to its distance to the park, proximity/availability of water (perennial/non-perennial rivers, dams), and land cover. These selected herdsmen recorded their grazing patterns three to five days per month, using a handheld GPS unit set to automatically record their location every $5 \mathrm{~min}$.

\subsection{Historical and other data}

A number of datasets on the KNP were made available by SANParks: annual buffalo census data, buffalo sightings by game rangers, and information on fence events for 2007 (CyberTracker data). A buffalo density map was produced based on estimates of the total number of buffaloes inside the park and an existing distribution map representing the concentration of buffaloes between January and April 2007 (Rodwell et al., 2001; Winterbach and Bothma, 1998). Four classes were defined: high density ( 7 or more buffaloes $/ \mathrm{km}^{2}$ ), medium density (between 5 and 7 buffaloes $/ \mathrm{km}^{2}$ ), low density (between 3 and 5 buffaloes $/ \mathrm{km}^{2}$ ), and other areas ( 1 or less buffalo $/ \mathrm{km}^{2}$ ).

When buffaloes are observed outside the park, they are either immediately destroyed or chased/transported back into the park. A database of the location of buffaloes observed and/or controlled outside the park for the period 1998-2007 was used to validate our model outputs. These records stem from monthly veterinary reports as well as interviews with officials performing stray buffalo control operations to improve the spatial accuracy of these reports. A total of 398 stray buffalo events were recorded (unpublished data, Van Schalkwyk et al.).

State Veterinary Services, Mpumalanga Province, South Africa provided spatial information on the fence - i.e., electrified or not, height, gate location - and records of some fence breakages. Furthermore, we collected information on the fence from the literature (Sutmoller et al., 2000) and through field observations, by travelling along segments of the fence.

A map of FMD control zones was obtained from the State Veterinary Services, Mpumalanga Province, South Africa. Three FMD control zones are defined: infected areas (i.e., inside the KNP and private reserves bordering the KNP), inspection zone with vaccination (outside the natural reserves), and inspection zone without vaccination.

\section{Model description}

We followed the standard ODD protocol (Grimm et al., 2006) to describe our model. Below, we provide an overview of the model and describe the key concepts that were part of the model design. 
The detailed model description, including specific rules and equations, is provided as an Supplementary data. EPIFMD was coded in NetLogo, a free software that offers a suitable platform for multiagent simulations (Wilensky, 1999). Unified Modelling Language (UML) diagrams (Booch et al., 2004) were used to describe the conceptual structure of the model.

\subsection{Overview}

\subsubsection{Purpose}

The model was developed to create risk maps of direct contact rates between buffaloes and cattle in space and time. The broader objective was to analyse and describe spatial factors influencing contact risk by examining the influence of the landscape. The model does not predict the risk of disease transmission per se, but only direct contact between buffaloes and cattle - i.e., the presence of a buffalo and cattle agents in the same cell, at the same time. The actual transmission rate of FMD virus due to contact between infected buffaloes and susceptible cattle is very poorly understood (Condy and Hedger, 1974; Dawe et al., 1994). Since transmission is not considered in the model, vaccination and its effect on transmission rates and risk of outbreaks occurring has been omitted.

\subsubsection{State variables and scales}

The elements responsible for the dynamics of FMD epidemics are populations, space and time. These elements make up the internal structure of the model. The class diagram represents the static structure of the model and displays the relations between all the classes that constitute the model (Fig. 3). This diagram represents the low-level entities with their elementary properties and the full set of variables making up the model.

Agents are either mobile or cell agents. The former are individuals or groups of individuals who can move from one cell to another. Cell agents are represented by a grid where each cell contains several values that can be modified at each model run. Some of the attributes of cell agents change according to global values of temperature, precipitation and seasonality. The mobile agents comprise two populations: buffaloes and domestic cattle. Buffaloes live within the KNP and are only able to leave the reserve when the fence is permeable. There are between 21,000 and 27,000 buffaloes in KNP, occupying specific habitats (SANParks, 2001-2007; Winterbach and Bothma, 1998; Rodwell et al., 2001). Herds tend to be non-migratory but their home range varies seasonally from 40 to $1000 \mathrm{~km}^{2}$ (Bastos et al., 2000; Huffman, 2007; Vosloo et al., 1996). Within this space, buffaloes move around to feed and drink (Ryan and Jordaan, 2005; Winterbach and Bothma, 1998). Due to computing constraints, one buffalo agent represents five individuals in the model, corresponding to the mean number of buffaloes in a typical small herd of animals ranging the landscape (Halley and Mari, 2004; Ryan et al., 2006). A buffalo agent is assigned a single life cycle - i.e., all five buffaloes belong to the same age cohort. The study area was estimated to contain around 4700 buffaloes, thus 940 buffalo agents (SANParks, 2001-2007). Buffaloes have two life stages: they are either calves or adults.

For domestic cattle, one agent in the model represents a herd of cattle as they always stay in groups. Every evening, the cattle return to their kraal. At daytime, cattle are herded 2-5 km away from villages to graze. The grazing paths of cattle herds were parameterised based on the tracking data. On average, there are 85 cattle owners per village (standard deviation of 29), and thus 690 herds in the study area (Livestock register data, State Veterinary Services, Mpumalanga, South Africa, 2007). The movements of all the mobile agents are mainly influenced by the location of water points. After drinking, they move toward high biomass rangelands.

Space is represented by a grid-based landscape with multiple layers representing land cover attributes. Space provides the envi- ronmental basis for movements and interactions of populations. The 210,000 cells of 100 by $100 \mathrm{~m}$ cover the study area on the western part of KNP (Fig. 1). This scale is a trade-off between a sufficient spatial resolution to represent the relevant agents involved in FMD transmission and computer processing time. Some spatial attributes vary through time: biomass, fence state, and hydrography. Proxy variables for biomass were derived from SPOT Vegetation imagery and were correlated with precipitation to derive rules of seasonal variations in vegetation. The fence is represented by a one pixel-wide line bordering the KNP. Fence breakages are represented by a stochastic rule that was calibrated based on data on fence breakage events, location of gates (SANParks 2004, State Veterinary Services, Mpumalaga Province, South Africa, 2007), and field observations. This rule simulates occasional fence destructions where it crosses rivers and in random locations for damage by humans or wildlife. The likelihood of fence repair was influenced by its accessibility. The state of the hydrographical network is influenced by monthly precipitation from the Worldclim database (Hijmans et al., 2005). Movements of animals are largely determined by the presence of water. Other attributes of cells are fixed parameters of the environment, represented as raster data: land cover type, FMD control zone, buffalo density, and accessibility.

Time was represented by discrete time steps corresponding to one-fifth of a day: night, morning, midday, afternoon and evening. This resolution allows representing the population dynamics and mobility as defined in the literature (Ryan and Jordaan, 2005; Winterbach and Bothma, 1998). A calendar was included to track time in days, weeks, months, and years to represent seasonal processes that influence animal behaviour, biomass growth, and water availability. Monthly mean temperature and precipitation were driving seasonal changes. Model simulations cover five years. Table 1 summarizes all parameters and variables of the model.

\subsubsection{Process overview and scheduling}

The behaviour of each group of agents controls contacts between buffaloes and cattle on the landscape over time. The processes running during each discrete time-step and their interactions are represented in a UML sequence diagram (Fig. 4). It provides an overview of the sequence of processes and the schedule of interactions betweens the different agents at each time-step. Each process is applied to a specific class of agent defined in the UML class diagram.

At each time-step, firstly the global variables (the time counter, temperature and precipitation) are updated. Then the values of cell agents change in the following sequence: biomass, hydrology, and the state of the fence. Next, the variables for buffaloes are updated as they move, reproduce and die. Finally, a similar process is applied to cattle. In each module, agents are processed in a random sequence. Variables are updated immediately during model runs. Some procedures are only activated under particular conditions - e.g., during the mating season, between January and April, movements of buffaloes are influenced by group cohesion.

\subsection{Design concepts}

\subsubsection{Observation}

A user-friendly interface was created to follow spatial and temporal variations in model outputs. Global level outputs, such as the number of buffaloes escaping the park, the number of contacts between wildlife and cattle, and the grazing pathways of animals were computed and visualised on plots and maps. Maps representing environmental variables were also produced to track seasonal and inter-annual changes in these variables. 


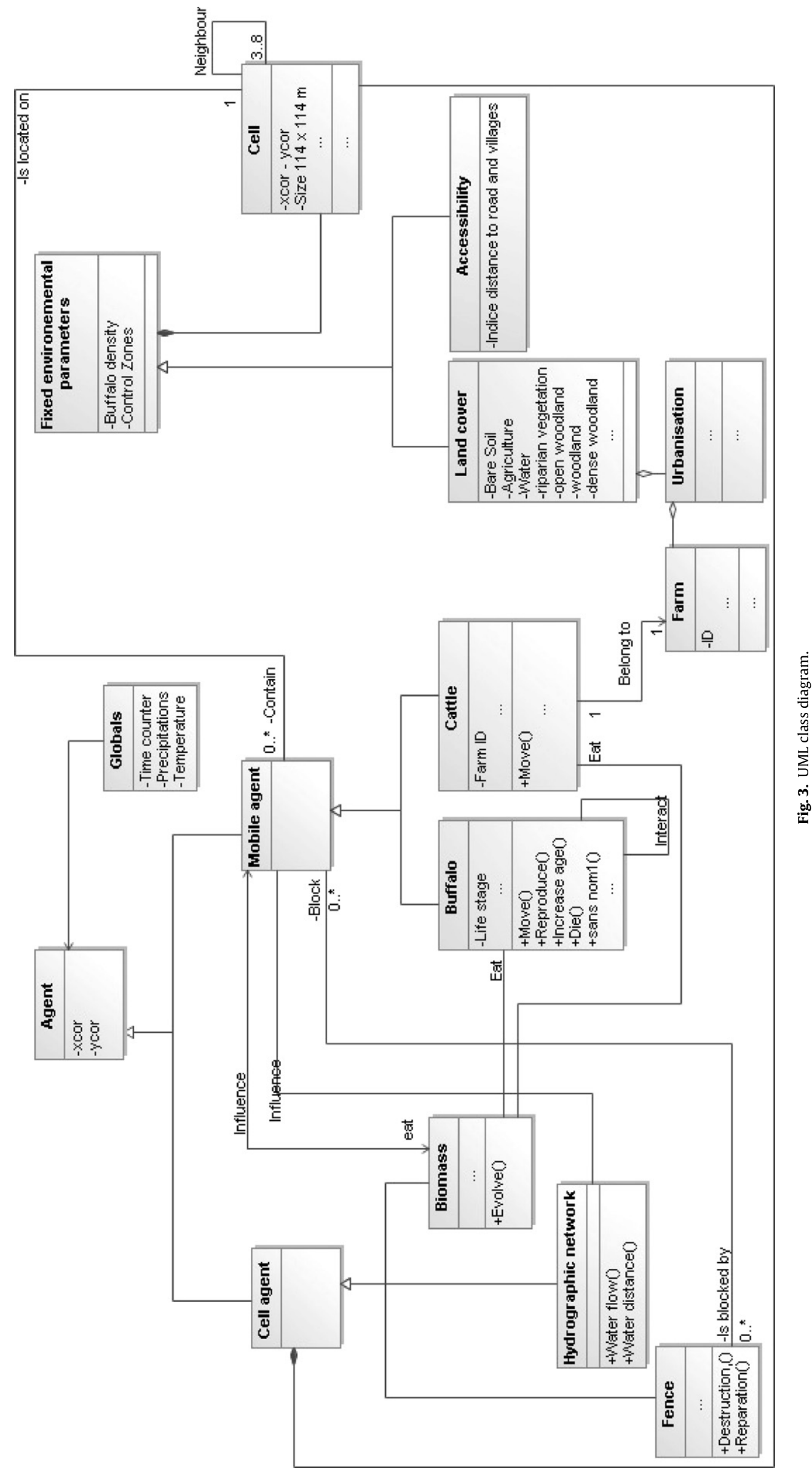


Summary of input variables and parameters.

\begin{tabular}{|c|c|c|c|c|c|c|c|c|}
\hline & & Variables/Parameters & Abbrev. & $\begin{array}{l}\text { Value or range value in EPIFMD } \\
\text { (standard values) }\end{array}$ & $\begin{array}{l}\text { Endogenous/ } \\
\text { exogenous }\end{array}$ & $\begin{array}{l}\text { Extreme values in } \\
\text { reality }\end{array}$ & $\begin{array}{l}\text { Extreme values in } \\
\text { sensitivity analysis }\end{array}$ & References \\
\hline \multirow{3}{*}{\multicolumn{2}{|c|}{ Global }} & Monthly mean temperatures $\left({ }^{\circ} \mathrm{C}\right)$ & $\mathrm{t}$ & 14.30 & exo & - & - & Worldclim \\
\hline & & Monthly precipitations (mm) & $\mathrm{pp}$ & $0-125$ & exo & - & - & Worldclim \\
\hline & & Time-step length (day) & $\mathrm{p}$ & $1 / 5$ & exo & - & - & \\
\hline \multirow[t]{14}{*}{ Cells } & \multirow[t]{4}{*}{ Map } & Land cover & LC & $\begin{array}{l}\text { Urbanised, cultivated, water, } \\
\text { riparian veg., low veg., medium } \\
\text { veg. and high veg. }\end{array}$ & exo & - & - & Epistis production: Spot classification \\
\hline & & Control zone of fmd & Czone & $\begin{array}{l}\text { Buffer area, inspection and free } \\
\text { area }\end{array}$ & exo & - & - & SANparks \\
\hline & & Buffalo density habitat map & Bders & $\begin{array}{l}\text { High density, medium density, } \\
\text { low density }\end{array}$ & exo & - & - & SANparks \\
\hline & & Accessibility map & Acces & Accessibility indice & exo & - & - & Epistis production \\
\hline & \multirow[t]{4}{*}{ Fences } & $\begin{array}{l}\text { Probability of fence destroyed } \\
\text { (breaks } / 100 \mathrm{~km} \text { of fence/year) }\end{array}$ & brk & $32.8 \pm 2.7(\mathrm{SD})$ & exo & $\begin{array}{l}\text { Difficult to } \\
\text { estimate }\end{array}$ & Wbrk+Rbrk & SANparks/Field data estimations \\
\hline & & $\begin{array}{l}\text { Probability of fence destroyed by water } \\
\text { (breaks } / 100 \mathrm{~km} \text { of fence/year) }\end{array}$ & Wbrk & $22.5 \pm 2.2(\mathrm{SD})$ & exo & $\begin{array}{l}\text { Difficult to } \\
\text { estimate }\end{array}$ & $18-27$ & SANparks/Field data estimations \\
\hline & & $\begin{array}{l}\text { Probability of fence destroyed } \\
\text { randomly (breaks } / 100 \mathrm{~km} \text { of } \\
\text { fence/year) }\end{array}$ & Rbrk & $10.3 \pm 1.3(\mathrm{SD})$ & exo & $\begin{array}{l}\text { Difficult to } \\
\text { estimate }\end{array}$ & $8.5-12.5$ & SANparks/Field data estimations \\
\hline & & Time that fence stays unrepaired (days) & & $5.5 \pm 2.5$ & exo & $\begin{array}{l}\text { Difficult to } \\
\text { estimate }\end{array}$ & $0.5-10.5$ & Field data estimations \\
\hline & \multirow[t]{2}{*}{ Biomass } & Ndvi range of vegetation & Biom & $-0.2-0.25$ & endo & - & - & $\begin{array}{l}\text { Gloveg project (Swinnen and Veroustraete, } \\
\text { 2008) }\end{array}$ \\
\hline & & $\begin{array}{l}\text { Const. Biomass influencing max } \\
\text { biomass in function of } t \text { and pp }\end{array}$ & biomax & 0.8 & exo & $\begin{array}{l}\text { Difficult to } \\
\text { estimate }\end{array}$ & $0.6-1$ & $\begin{array}{l}\text { Equation defined based NDVI cycle of } \\
\text { vegetation }\end{array}$ \\
\hline & \multirow[t]{4}{*}{ Hydrographic } & Binary water-map & Water & 0 or 1 & endo & 0 or 1 & - & Ruled base on filed data observation \\
\hline & & Distance to water & Dist & $0-1$ & endo & $0-1$ & - & $\begin{array}{l}\text { Map calculated on the basis of distance from } \\
\text { river }\end{array}$ \\
\hline & & Total water (in Netlogo ref.) & Twat & 500 & exo & $\begin{array}{l}\text { Computer } \\
\text { modelling value }\end{array}$ & $401-600$ & Calculated iteratively with gps field data \\
\hline & & $\begin{array}{l}\text { Importance of a water drop on the } \\
\text { water flow }\end{array}$ & w-drop & 2.5 & exo & $\begin{array}{l}\text { Computer } \\
\text { modelling value }\end{array}$ & $1.5-3.6$ & Calculated iteratively with gps field data \\
\hline \multirow[t]{10}{*}{ Agents } & \multirow[t]{7}{*}{ Buffaloes } & Density of buffaloes in the area & $\mathrm{Db}$ & $1.1-1.7$ & exo & $1.1-1.7$ & $1.1-1.7$ & $\begin{array}{l}\text { SANparks, Winterbach 98, Rodwell et al., } \\
2001\end{array}$ \\
\hline & & Reproduction rate & $\mathrm{R}$ & $8.4 \pm 0.98 \%(S D)$ & exo & $7-13 \%$ & $7-13 \%$ & $\begin{array}{l}\text { Jolles (2007), Pienaar (1969), Caron et al., } \\
2003\end{array}$ \\
\hline & & Mortality rate adult & Ma & $8.51 \pm 1.24 \%(\mathrm{SD})$ & endo & $3-17 \%$ & $3-17 \%$ & $\begin{array}{l}\text { Jolles (2007), Pienaar (1969), Caron et al., } \\
2003\end{array}$ \\
\hline & & Mortality rate calf & Mc & $17.5 \pm 4.33 \%(\mathrm{SD})$ & exo & $14-21 \%$ & $14-21 \%$ & $\begin{array}{l}\text { Jolles (2007), Pienaar (1969), Caron et al., } \\
2003\end{array}$ \\
\hline & & $\begin{array}{l}\text { Percentage of buffaloes killed outside } \\
\text { the park }\end{array}$ & KOut & $5.50 \pm 0.85 \%$ & endo & $\begin{array}{l}\text { Difficult to } \\
\text { estimate }\end{array}$ & $\begin{array}{l}\text { Buffaloes outside } \\
\text { the park }\end{array}$ & \\
\hline & & Distance moved/day & $\mathrm{Db}$ & $\begin{array}{l}7-10 \mathrm{~km} \text { (central value } \\
\text { used }=9 \mathrm{~km})\end{array}$ & endo & $7-10 \mathrm{~km} /$ day & $8-10 \mathrm{~km}$ & Sinclair (1977) and Ryan et al. (2006) \\
\hline & & $\begin{array}{l}\text { Constant defining extreme values for } \\
\text { the total move } \rightarrow \text { Define number of } \\
\text { pixel cross/day }\end{array}$ & Cqmb & $\begin{array}{l}-0.09 \text { to }-0.01 \\
80-100\end{array}$ & $\begin{array}{l}\text { exo } \\
\text { endo }\end{array}$ & $\begin{array}{l}\text { Computer } \\
\text { modelling value }\end{array}$ & $\begin{array}{l}-0.07 \text { to }-0.03 \\
80-100\end{array}$ & Sinclair (1977) and Ryan et al. (2006) \\
\hline & \multirow[t]{3}{*}{ Cattle } & Number of cattle herds & $\mathrm{Nbc}$ & 668 & exo & 650 & $534-802$ & $\begin{array}{l}\text { State Vet. Ser., Dept. of Agriculture, } \\
\text { Mpumalanga and Limpopo Prov., SA, } \\
\text { 2003-2007 }\end{array}$ \\
\hline & & Distance moved/day (in km) & Dc & $3-6 \mathrm{~km}$ & exo & $3-5 \mathrm{~km}$ & $3-6 \mathrm{~km}$ & Epistis data \\
\hline & & $\begin{array}{l}\text { Constant defining extreme values for } \\
\text { total } \rightarrow \text { Define number of pixel } \\
\text { cross/day }\end{array}$ & Cqme & $\begin{array}{l}100-300 \\
10-70 \mathrm{~km}^{2}\end{array}$ & $\begin{array}{l}\text { exo } \\
\text { endo }\end{array}$ & $\begin{array}{l}\text { Computer } \\
\text { modelling values }\end{array}$ & $\begin{array}{l}100-300 \\
10-70 \mathrm{~km}^{2}\end{array}$ & Epistis data \\
\hline
\end{tabular}




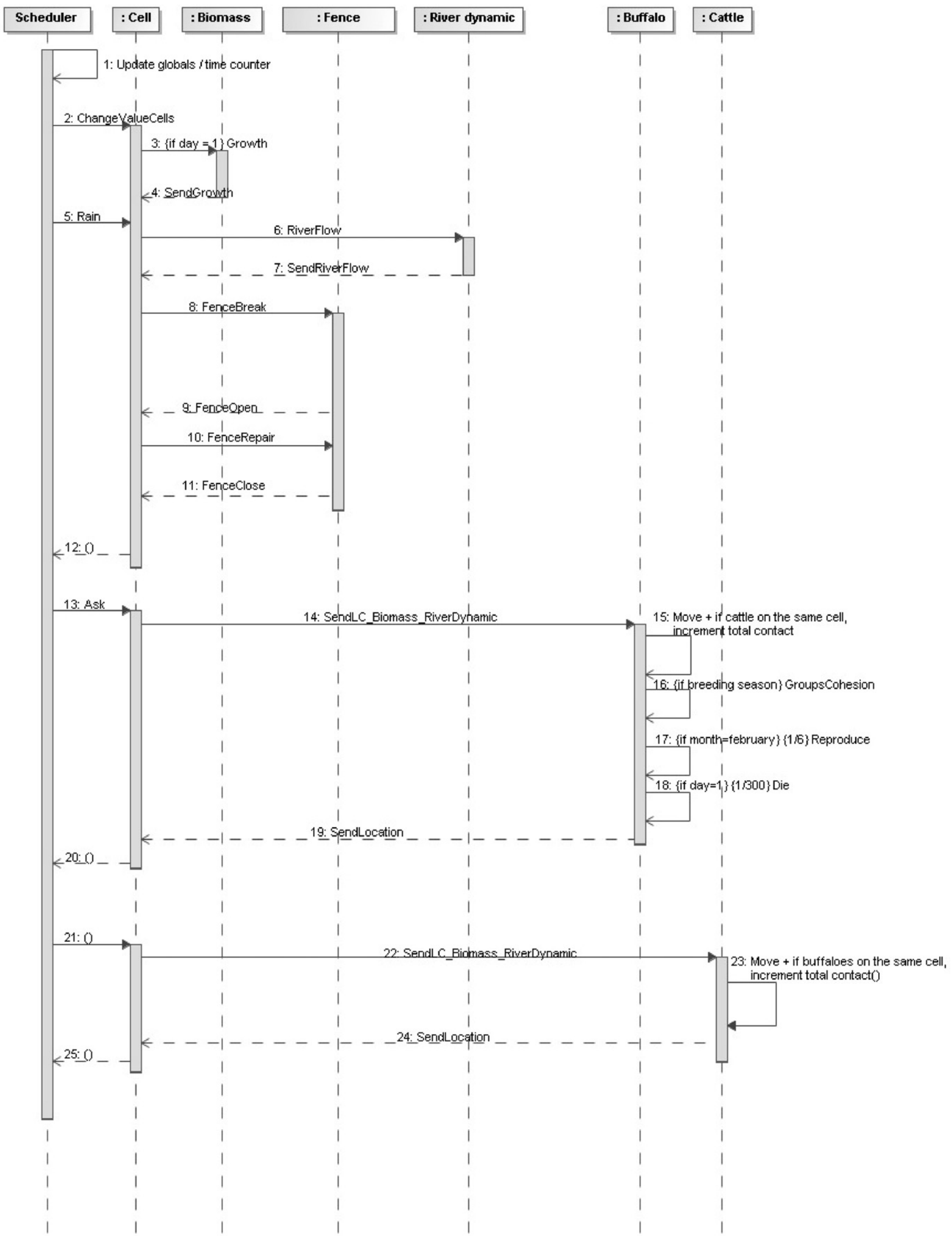

Fig. 4. UML sequence diagram. 
Table 2

Percentage of output variation per percent of input variation of key parameters.

\begin{tabular}{|c|c|c|c|}
\hline Parameter number & & Buffaloes escaping the park & Contacts between buffaloes and cattle \\
\hline 1 & Fence breaks near rivers & 0.45 & 0.33 \\
\hline 2 & Random fence breaks & 0.43 & 0.29 \\
\hline 3 & Duration of fence breaks & 0.82 & 0.84 \\
\hline 4 & Biomass & -0.08 & 0.28 \\
\hline 5 & Volume of rain & -0.23 & -0.30 \\
\hline 6 & Water height & -0.04 & 0.03 \\
\hline 7 & Quantity of movement, buffaloes & 1.01 & 0.94 \\
\hline 8 & Quantity of movement, cattle & -0.04 & 1.07 \\
\hline
\end{tabular}

\subsubsection{Sensing}

Animals react to external environmental factors such as temperature and precipitation, which influence animal activities, the biomass cycle, and the hydrographical network.

\subsubsection{Interactions and emergence}

A main feature of the modelled system is the emergence of contacts between animals from different species, in particular buffaloes and cattle. Spatiotemporal dynamics of contacts are influenced by changes in the global state of the system, which affect interactions between animals and the landscape. Mobile agents move independently from each other. Each individual adapts and optimises his movements by preferentially selecting cells with high food resources and water availability. Within the population of buffaloes, the disease dynamics is linked with births, since calves between three and eight months of age are very infectious (Bastos et al., 2000).

\subsubsection{Stochasticity}

Random events were introduced in the model to represent landscape heterogeneity and seasonal and interannual climatic variability. A realistic pattern of variability was introduced into deterministic rules by defining Gaussian probability distribution functions that were calibrated using observations. For example, the stochasticity of mobiles agents was represented by varying their locations in the landscape during the initialisation of each model run and by introducing a random element in animal movements. The population dynamics of buffaloes includes a random selection of individuals who reproduce and die at each time step.

\section{Model consistency}

After model parameterisation, one has to evaluate the quality of the outputs to determine whether the MAS is a realistic and useful representation of the actual system. MAS cannot be validated in the same way as traditional simulation models given the complex nature of the system, with multiple interactions and emerging properties (Niazi et al., 2009). No set of specific validation tests are easily applicable to MAS (Sargent, 2009). Therefore, several techniques and tests were used simultaneously here to verify the model consistency.

\subsection{Exploration and verification of EPIFMD}

The first stage after the creation of a MAS, is to ensure that the model works correctly and that the computer code is free from programming errors (Kleijnen, 1995; Niazi et al., 2009; Sargent, 2009). As a first test, the conceptual representation of EPIFMD was explained to experts to evaluate whether the input-output relations were intuitively acceptable. Secondly, a visual examination of the animations and graphs generated by multiple model runs increased the confidence that the model behaved consistently with the conceptual model (Law, 2008). We analysed both the overall model behaviour, and specific routines and submodels to detect programming and conceptual errors. As a third exploratory step, preliminary simulations were conducted on selected variables to evaluate the output responses. In particular, a linear increase in the number of buffalo and cattle herds was introduced to observe whether it was producing a linear increase in the number of buffaloes outside the park and in the number of buffalo-cattle contacts.

\subsection{Sensitivity analysis}

Sensitivity analysis consists of changing the values of inputs and parameters of a model by simulation experiments to explore the effect on the model's behaviour and output variables. This stage was particularly important given the uncertainties with regard to some of the model parameters. It identified which parameters whose level of uncertainty was high, had a large impact on the model behaviour and therefore had to be refined (Sargent, 2009).

We first applied the most common approach to sensitivity analysis where parameter values are modified one by one - the "One At a Time analysis" (OAAT) - to measure the influence of each input on outputs (Beres and Hawkins, 2001). The outputs were the number of buffaloes outside the park and the number of buffalo-cattle contacts. All the parameters with an uncertain value were tested for their sensitivity. For each of these parameters, high and low values were identified based on the literature, field data and expert knowledge. This approach better captured the specific level of uncertainty for a given parameter, rather than the more common method of applying a fixed increment ( $\pm 10-20 \%$ from the baseline value). Eight parameters were evaluated (Table 2) and for each parameter, four values were tested (lower and upper extreme and two intermediate values), in addition to the baseline (central) value. Fifty replications of each configuration were tested to determine the level of internal stochastic variability of the model. Thus, the model was run 250 times for each parameter. To compare the influence of parameters on the model outputs, values of inputs and outputs were normalised with a central value of 100 for the baseline. This normalisation was then used to calculate for each parameter a percentage of output variation for each percent of input variation (Table 2).

This method does not capture potential interactions between parameters, even though a MAS represents a complex system for which the result of the model is more than the addition of all the rules. Multivariate methods for sensitivity analyses drastically increase the number of potential pairwise interactions between parameters. Simulations with only an upper and a lower value required $2^{n}$ simulation runs per configuration, where $n$ is the number of parameters. In our case, it would amount to 1600 simulations for the 5 most important parameters only, with 50 runs per configuration. Including 8 parameters would require 25,600 simulations.

Several methods to reduce the number of model runs for multivariate analyses have been developed. We used the Plackett-Burman design (PB design) method that provides an experimental design for investigating the dependence of some measured quantity on a number of factors, using a limited number of experiments (Plackett and Burman, 1946, in Beres and Hawkins, 
Table 3

Ranking of score values obtained by the PB design method for: (a) buffaloes escaping the park and (b) contacts between buffaloes and cattle.

\begin{tabular}{|c|c|c|c|}
\hline \multicolumn{4}{|c|}{ Buffaloes escaping the park } \\
\hline \multicolumn{2}{|c|}{ Score of individual parameters } & \multicolumn{2}{|c|}{ Score of parameter interactions } \\
\hline Parameter 7 & 102.61 & Parameter $3 \times$ Parameter 7 & 45.48 \\
\hline Parameter 3 & 76.4225 & Parameter $4 \times$ Parameter 7 & -3.3925 \\
\hline Parameter 5 & -5.1075 & Parameter $5 \times$ Parameter 7 & -2.08 \\
\hline Parameter 4 & -3.985 & Parameter $3 \times$ Parameter 5 & -2.075 \\
\hline \multirow[t]{3}{*}{ Parameter 8} & -2.795 & Parameter $3 \times$ Parameter 8 & -1.4225 \\
\hline & & Parameter $7 \times$ Parameter 8 & -1.315 \\
\hline & & Parameter $3 \times$ Parameter 5 & -1.3075 \\
\hline
\end{tabular}

Contacts between buffaloes and cattle

\begin{tabular}{|c|c|c|c|}
\hline \multicolumn{2}{|c|}{ Score of individual parameters } & \multicolumn{2}{|c|}{ Score of parameter interactions } \\
\hline Parameter 8 & 84.0075 & Parameter $7 \times$ Parameter 8 & 44.61 \\
\hline Parameter 7 & 69.765 & Parameter $3 \times$ Parameter 8 & 35.8925 \\
\hline Parameter 3 & 68.4775 & Parameter $3 \times$ Parameter 7 & 30.975 \\
\hline Parameter 4 & 7.625 & Parameter $4 \times$ Parameter 7 & 4.0925 \\
\hline \multirow[t]{3}{*}{ Parameter 5} & -6.685 & Parameter $4 \times$ Parameter 8 & -1.635 \\
\hline & & Parameter $5 \times$ Parameter 7 & -1.1025 \\
\hline & & Parameter $5 \times$ Parameter 8 & 0.16 \\
\hline
\end{tabular}

2001). The experiment is constructed based on a Hadamard matrix - a square matrix whose entries are either +1 or -1 and whose rows are mutually orthogonal (Plackett and Burman, 1946). This is a prescriptive methodology using pre-determined designs. It requires approximately twice the number of parameters times the number of runs per configuration. For five parameters, it required 800 simulations, and 1200 simulations for 8 parameters. Compared to Monte Carlo simulations, which is often used for sensitivity analysis of MAS, this methodology requires less simulations to obtain similar results (Claeys-Bruno et al., 2009). PB design only considers pairwise interactions and not higher order interactions. This is acceptable given the sparsity-of-effects principle, stating that "a system is usually dominated by main effects and low-order interactions" (Wu and Hamada, 2000). The individual parameters and 2 -way interactions are therefore expected to have the most significant influence on outputs. The successive stages required to implement the PB methodology, illustrated by an example, are described in Beres and Hawkins (2001).

Firstly, only the five most influential parameters - as identified by the OAAT methodology - were selected for the PB methodology and only their upper and lower values were tested. The second step consisted in selecting the appropriate Plackett-Burman pattern given the number of parameters (Plackett and Burman, 1946). These patterns are strings of ordered pluses and minuses. The designs come in sizes that are multiples of four. To select an adequate pattern, the number of signs in the list $n$ must be smaller than, but as similar as possible to the design size $d(n<d)$. PB patterns provide the string of $d-1$ signs. Thirdly, the Plackett-Burman sensitivity analysis matrix was created. This is an array of signs where the top row is the PB pattern. Each subsequent row is constructed by a cyclic permutation, one by one, of the top row to obtain $d-1$ rows. A row with only minuses is then added. An additional set of $d$ new rows is also created, with the opposite signs of the $d$ first rows (Fig. 5). Each row of the PB matrix specifies a distinct scenario of the model and each column is associated with a parameter. If the number of parameters is lower than the number of columns (i.e. $n<(d-1)$ ) - as they are multiples of four - then the surplus of columns is ignored. The signs in the matrix indicate whether the upper or lower extreme values were selected for each parameter. A model run is performed for each scenario - $2 d$ scenarios - with 50 replications per scenario.

The output value of each scenario was used to evaluate the effect of each parameter. It is calculated by the sum of the signed out-

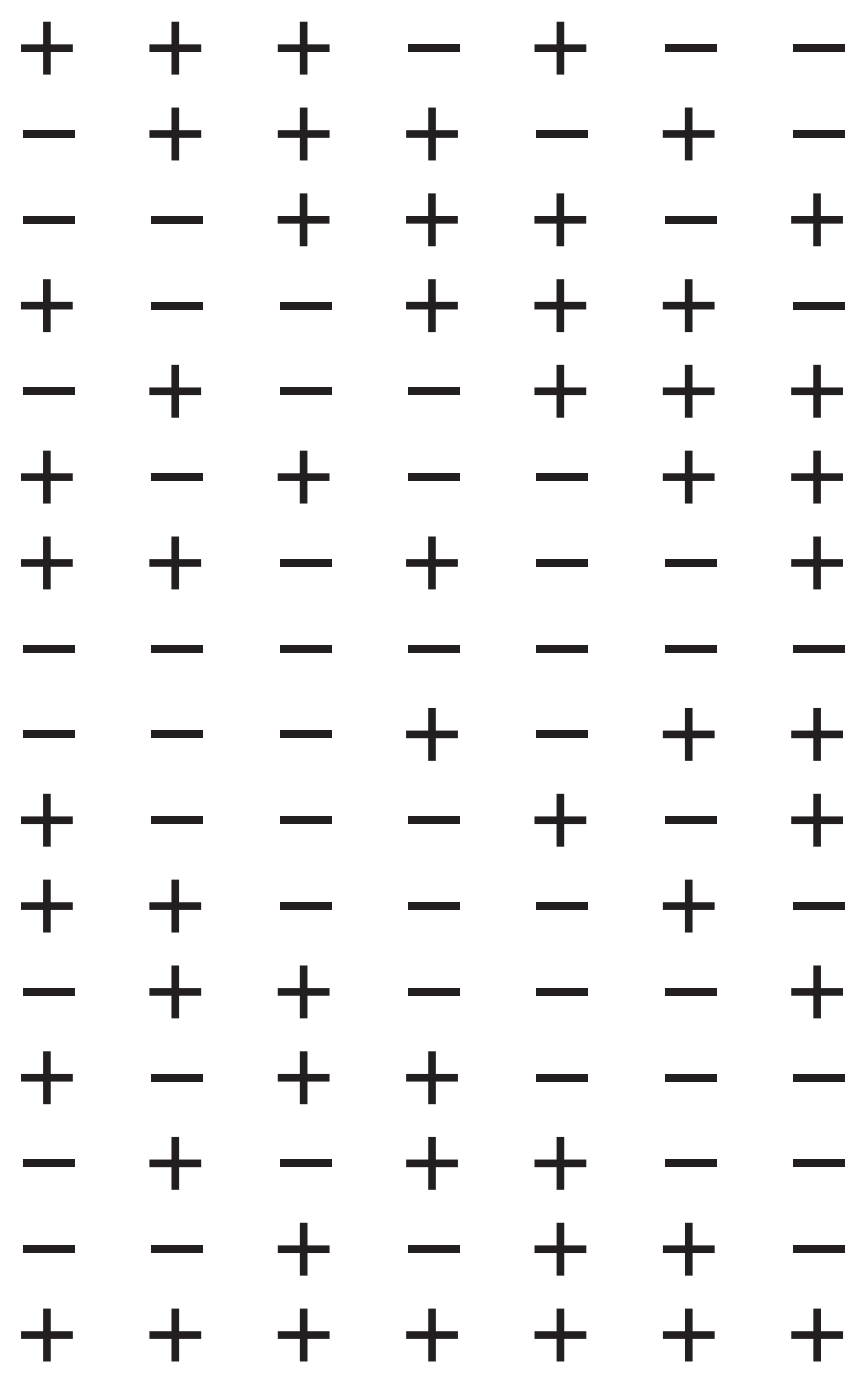

Fig. 5. Complete PB matrix.

puts - as derived from the PB matrix - divided by the design size $d$ of the PB matrix (eight in our case). The scores obtained for each parameter were sorted (Table 3 ). Higher absolute values indicate a larger influence of the parameter. The sign of the score indicates the direction of change: positive scores indicate an increase in the response when the parameter value increases and negative scores mean a decrease in the response with an increase in the parameter value. This ranking of parameters associated with the greatest model sensitivity was compared with the OAAT ranking.

The next step was the calculation of the two-way interactions of parameters. All parameters were combined 2 by 2, creating a matrix of signs with $\left(n^{2}-n\right) / 2$ columns (with $n$ the number of parameters), each column representing one of the possible pairs. The signs of the two individual parameters were multiplied row by row to create the new matrix of signs. The output of each scenario was associated with these derived signs - as in the previous step and the (signed) outputs were summed and divided by $d$ to obtain the scores. The score value for each two-way interaction was then sorted as for individual parameters (Table 3). A high score for interaction effects means that the pair of parameters acts in concert to produce an effect that is over and above the sum of the individual effects of the two parameters (Beres and Hawkins, 2001). The higher the score value, the more the two parameters mutually rein- 


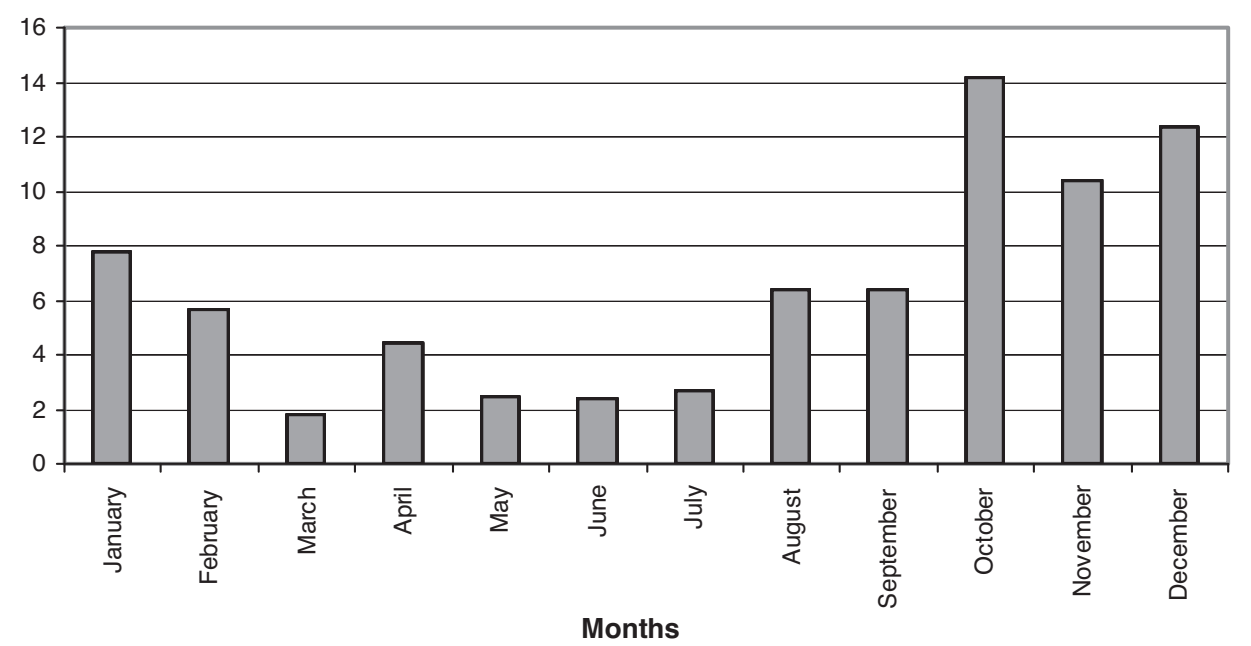

Fig. 6. Mean number of contacts between buffaloes and cattle per month.

force their effects to increase variation in output values. Note that aliasing interactions could lead to identical scores for more than one pair, which may blur the interpretation (Beres and Hawkins, 2001). All the pairs with the same score are members of an alias group and the effect on the score is the effect of the influence from more than one pair. The analysis of the scores was based on the assumption that the pairs within an alias group with the most significant score for individual parameters are the ones responsible for most of the group's effect. In that case, the other pairs may be disregarded based on the scarcity of effects principle. "The observed effects are the result of a linear combination of the pairs having the same outcomes from the calculation procedure and the coefficients for some of the terms in the linear combination are very small, making those terms negligible" (Beres and Hawkins, 2001).

\subsection{External consistency}

To evaluate whether it is realistic within its domain of applicability, a MAS needs to be validated at least at two organisational levels. At the object level, model subsets were calibrated simultaneously with the elaboration of rules based on empirical observations. At the level of emergent properties, a validation of model outputs that reflect interactions between agents increase the confidence that the model is able to reproduce macro-level dynamics. For this, we used historical data on locations of buffaloes killed outside the park over 10 years. These data were compared with simulated maps of the probability of presence of buffaloes outside the park. Given the non-exhaustive character of the observed data, one cannot validate the absolute number of buffaloes escaping the park but rather their spatial distribution outside the park with respect to landscape features. The relevant landscape attributes were the distances to perennial rivers, to all rivers, and to settlements. We also compared the buffalo distribution outside the park to a set of locations randomly distributed outside the park, to test whether the buffaloes are distributed near specific areas.

\section{Results}

\subsection{Exploration and verification of EPIFMD}

The model outputs are the grazing pathways of cattle and buffaloes, the number of buffaloes escaping the park, and the number of buffalo-cattle contacts. These variables were visualised spatially, on graphs (Fig. 6) and on land cover maps (Fig. 7). Initial model explorations revealed that EPIFMD outputs agree with expert opinions and do not produce anomalous or counter-intuitive results.

\subsection{Sensitivity analysis}

The sensitivity analysis identified the model parameters with uncertain values that had the greatest influence on model outputs. The home ranges of buffaloes and of cattle strongly influence the output values: a $1 \%$ variation in input gives a variation of around $1 \%$ in output (Table 2 ). Actually, movements over longer distances increase the likelihood of contact with other animals. Values for these parameters are still slightly uncertain, in particular for buffaloes, but refining them further would require GPS tracking data.

The following three parameters - fence breakages caused by water, random fence breakages, and time between fence breakage and repair - influence both when and for how long the fence is open, and thus allow buffaloes to exit the park. The model outputs are also sensitive to these parameter values: a $1 \%$ input variation leads to a $0.8 \%$ output variation (Table 2 ). These are the most uncertain parameters given the incomplete field data on these events. For the PB methodology, these three parameters were aggregated in a single one, defined as the time between fence breakage and repair. Unexpectedly, the location of fence breakages - near water points or randomly distributed - does not influence model outputs.

For the remaining parameters, a $1 \%$ variation in input leads to less than $0.3 \%$ of output variation (Table 2 ). They were therefore not used in the PB analysis. The reproduction rate and mortality rate of buffalo calves only influence contacts between buffalo calves and cattle. As calves represent a small fraction of the total population of buffaloes, their influence on the model output - number of buffalo-cattle contacts - is relatively limited. While this study did not explicitly consider transmission per se, the significance of these cattle-buffalo calf contacts, albeit few, on transmission was not estimated. The water height, a parameter defining the rule for water flow, influences the river sub-model but this effect is diluted in the overall model and therefore has only a weak influence on model outputs

Results from the OAAT methodology show a strong relation between variations in the number of buffaloes escaping the park and buffalo-cattle contacts, except for parameters associated with cattle and the biomass cycle (Table 2). Cattle do not influence buffaloes escaping from the park. Biomass consumed by cattle causes vegetation cover to decrease, which increases the contrast between overgrazed areas around villages and more remote areas. Stray buf- 

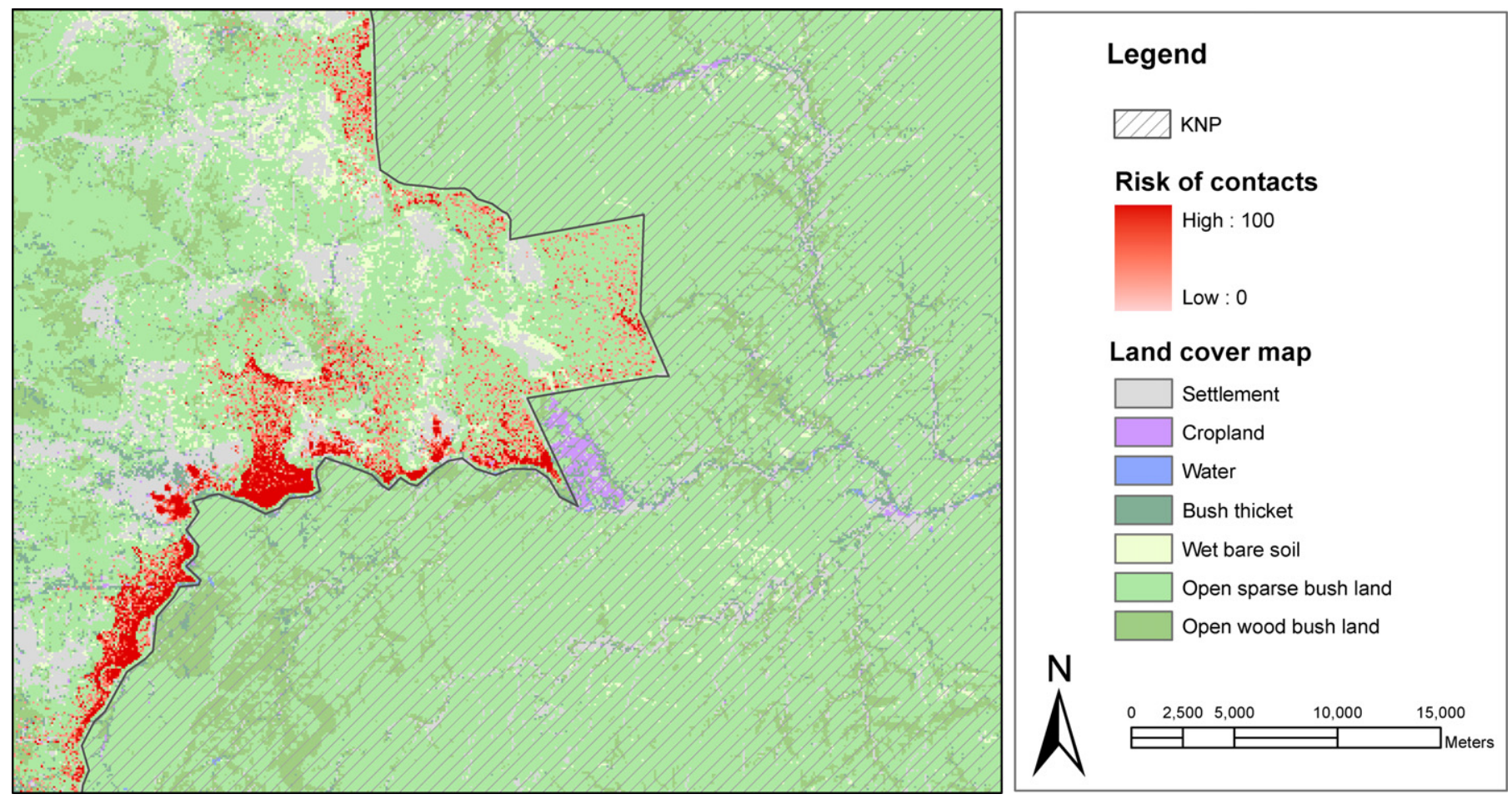

Fig. 7. Map of high contact areas showing the presence of buffaloes outside the park.

faloes tend to concentrate on patches with higher biomass, thus located in these remote areas.

The same level of influence and direction of change was obtained for each parameter with the PB design and OATT methodologies for the model sensitivity calculated for individual parameters (Table 3(a) and (b)). For buffaloes escaping the park, only the interaction between the time between fence breakage and repair, and the quantity of movement of buffaloes was important in the two-way analysis (Table 3(a)). For the number of contacts, three interactions were important: between the quantity of movement of cattle and the quantity of movement of buffaloes, between the quantity of movement of cattle and the time between fence breakage and repair, and between the time between fence breakage and repair with the quantity of movement of buffaloes (Table 3(b)).

\subsection{External consistency}

Comparing the location of buffaloes killed outside the park with the maps of their location predicted by the model reveals similar spatial distributions, mainly for the distance to perennial rivers (coefficient of determination $r^{2}=0.87$ ). We found weak linear relations between the set of random locations that were generated and, on one hand, field observations $\left(r^{2}=0.14\right)$ and, on the other hand, model predictions $\left(r^{2}=0.10\right)$. Similar results were obtained for the comparison between mean distances to perennial rivers: a mean value of $3333 \mathrm{~m}$ was obtained for the buffaloes killed outside the park, of $3268 \mathrm{~m}$ for the model predictions, and of $4227 \mathrm{~m}$ for the random locations. For the distance to all rivers, which have a higher density network, field observations have a mean value of $165 \mathrm{~m}$, model predictions of $147 \mathrm{~m}$, and random locations of $207 \mathrm{~m}$. Buffaloes thus tend to concentrate close to rivers. For the distance to settlements, the three distributions were in agreement.

\section{Discussion}

Our sensitivity analysis reveals that the landscape configuration is a key factor explaining buffalo-cattle contacts given its influence on cattle and buffalo movements. Spatial and temporal variations in risk of contacts were well captured by our model. The main factors influencing buffalo-cattle contact are the range of displacements of cattle and buffaloes, and the number of fence breakages multiplied by the time between breakage and repair. A large number of fence breakages that are repaired rapidly have the same influence as a few breakages that remain unrepaired for several days. The location of breakages does not seem to influence the risk of contact, which is an unexpected result. As buffaloes move along directions that are more or less perpendicular to rivers - after drinking once per day, they move toward high biomass patches - they may encounter fence openings anywhere along their displacements. Fences are important elements in the control of FMD transmission, although they are criticised for their ecological impacts (they interfere with wildlife's migratory routes) and their social and economic costs are high (Vosloo et al., 2002). From a disease control point of view, very little can be done with regard to grazing movements of cattle and buffaloes. Therefore, the most critical intervention to reduce cattle-buffalo contacts conclude by the model, and thus FMD transmission risk, would be to intensify fence monitoring and repairs.

Our model simulations showed that contacts take place not only close to water-points but also in grazing areas, within an area up to $6 \mathrm{~km}$ from the fence. The most frequent contact area is in the vicinity of the Sabie River, an important perennial river flowing inside the KNP along its fence. Contacts mainly occur in open woodlands, bushlands, open sparse bushed area, and subsistence cultivation areas when fields are not cultivated. Fewer contacts occurred in settlements, bare soil areas with sparse vegetation, and thickets.

The results from simulation experiments were consistent with field observations. This increased the confidence in the model, although the availability of true validation data was limited. Comparisons between field data and model predictions were restricted to the spatial distribution of buffaloes. Field observations were also used to calibrate individual sub-models through iterative procedures.

The main limitation of the EPIFMD model is a lack (or low accuracy) of calibration data. Moreover, the biology of FMD virus 
transmission between buffaloes and cattle in an African context is not well understood. Therefore, the model represents contacts between cattle and buffaloes rather than the actual disease transmission. Although several studies on buffalo behaviour have been conducted (Cross et al., 2005; Ryan and Jordaan, 2005; Sinclair, 1977; Winterbach and Bothma, 1998), these are not sufficiently detailed for fine-scale modelling. As some of these elements will become better known, they could easily be integrated into EPIFMD, since a MAS can be improved incrementally.

In follow-up work, the EPIFMD model will be used to test various hypotheses based on the dynamics of contact between cattle and buffaloes, by modifying exogenous variables and parameters of the model. We will explore scenarios that include changes in landscape configuration (e.g., landscape fragmentation and heterogeneity, land-use changes, increase in human population and expansion of settlements) and climatic changes (e.g., droughts and rainfall variability). This will allow exploration of non-linear impacts of exogenous variables of the model, such as climatic conditions, on output responses. Climate indirectly influences animal behaviour, biomass, rivers and fence permeability due to flooding. The usefulness of the model to assist local veterinary authorities will also be evaluated.

To our knowledge, EPIFMD is one of the first studies to model the spatial risk of FMD transmission, based on wildlife-livestock contact, in an integrated way, with a focus on landscape attributes as major elements influencing outbreaks. This model provides a solid basis to study spatial influences on wildlife-livestock contact and hence possible transmission of viral diseases at the interface between wildlife conservation areas and traditional farming areas.

\section{Conclusion}

EPIFMD provides a tool to better understand the influence of environmental factors on the contact rate between buffaloes and cattle, which is an important variable influencing transmission of FMD in African savannahs. Results show that these contacts mostly depend on the range of displacements of cattle and buffaloes, as influenced by the landscape configuration, and on the number of fence breakages multiplied by the time between breakage and repair. Contacts take place not only close to water-points but also in grazing areas. The spatiotemporal dynamics of contacts between domestic and wild animals is an emergent property of a complex system where each agent makes decisions based on climatic and landscape factors. The dynamics of each animal population is the result of actions by individuals. Individuals adapt and optimise their movements by preferentially selecting cells with high biomass and water availability. Within buffalo populations, the dynamics of the disease is linked with synchronous birth cycles, as calves play an important role in FMD transmission (Gainaru et al., 1986).

A pragmatic approach to control outbreaks of the disease is to limit contact between the two populations. A better understanding of the factors influencing contact can improve the spatial management of the disease control zones around natural reserves. The MAS allows integrating multiple factors and visualising spatial and temporal dynamics of multiple agents and their interactions. With this user-friendly interface, spatial and temporal variations can be examined with spatial visualisation tools. The EPIFMD could easily be adapted to areas other than the KNP by only changing a few variables such as the number of animals, temperature and precipitation data, and landscape map layers.

\section{Acknowledgments}

This research was funded by the Belgian Science Policy, Research Program for Earth Observation Stereo II, contract no. SR/00/102, as part of the EPISTIS project (Remote sensing tools to study the EPIdemiology and Space/Time dynamicS of diseases). We are grateful to AVIA-GIS, S. Vanhuysse, C. De Pus, E. De Clercq, and N. Fostier for help in fieldwork and to P. Van den Bossche and S. Vanwambeke for their helpful suggestions. We thank the reviewers for their useful comments.

\section{Appendix A. Supplementary data}

Supplementary data associated with this article can be found, in the online version, at doi:10.1016/j.ecolmodel.2011.03.026.

\section{References}

Alexandersen, S., Quan, M., Murphy, C., Knight, J., Zhang, Z., 2003. Studies of quantitative parameters of virus excretion and transmission in pigs and cattle experimentally infected with foot-and-mouth disease virus. Journal of Comparative Pathology 129 (4), 268-282.

Barrett, J.C., 1992. The economic role of cattle in communal farming systems in Zimbabwe. Pastoral Development Network paper 32b. London, Overseas Development Institute (ODI), 35 pp.

Bastos, A.D.S., Boshoff, C.I., Keet, D.F., Bengis, R.G., Thomson, G.R., 2000. Natural transmission of foot-and-mouth disease virus between African buffalo (Syncerus caffer) and Impala (Aepyceros melampus) in the Kruger National Park, South Africa. Epidemiology and Infection 124 (3), 591-598.

Bates, T.W., Thurmond, M.C., Carpenter, R.E., 2003. Description of an epidemic simulation model for use in evaluating strategies to control an outbreak of footand-mouth disease. American Journal of Veterinary Research 64 (2), 195-204.

Beres, D.L., Hawkins, D.M., 2001. Plackett-Burman technique for sensitivity analysis of many-parametered models. Ecological Modelling 141 (1-3), 171-183.

Bithell, M., Brasington, J., Richards, K., 2008. Discrete-element, individual-based and agent-based models: tools for interdisciplinary enquiry in geography? Geoforum 39, 625-642.

Bonnell, T.R., Sengupta, R.R., Chapman, C.A., Goldberg, T.L., 2010. An agent-based model of red colobus resources and disease dynamics implicates key resource sites as hot spots of disease transmission. Ecological Modelling 221 (20), 2491-2500.

Booch, G., Rumbaugh, J., Jacobson, I., 2004. The Unified Modeling Language User Guide. Addison-Wesley, Boston, USA, 482 pp.

Brückner, G., Vosloo, W., Du Plessis, B., Kloeck, P., Connoway, L., Ekron, M., Weaver, D., Dickason, C., Schreuder, F., Marais, T., Mogajane, M., 2002. Foot and mouth disease: the experience of South Africa. Revue scientifique et technique (International Office of Epizootics) 21 (3), 751-764.

Caron, A., Cross, P.C., Toit, J.T., 2003. Ecological implications of bovine tuberculosis in african buffalo. Ecological Applications 13, 1338-1345.

Claeys-Bruno, M., Dobrijevic, M., Phan-Tan-Luu, R., Sergent, M., 2009. A new class of supersaturated design: application to a sensitivity study of a photochemical model. Chemometrics and Intelligent Laboratory Systems 95 (1), 86-93.

Condy, J.B., Hedger, R.S., 1974. The survival of foot and mouth disease virus in African buffalo with non transference of infection to domestic cattle. Research in Veterinary Science 16 (2), 182-185.

Cross, P.C., Lloyd-Smith, J.O., Getz, W.M., 2005. Disentangling association patterns in fission-fusion societies using African buffalo as an example. Animal Behaviour 69 (2), 499-506.

Dawe, P.S., Sorensen, K., Ferris, N.P., Barnett, I.T., Armstrong, R.M., Knowles, N.J., 1994. Experimental transmission of foot-and-mouth disease virus from carrier African buffalo (Syncerus caffer) to cattle in Zimbabwe. Veterinary Record 134 (9), 211-215.

Diggle, P.J., 2006. Spatio-temporal point processes, partial likelihood, foot and mouth disease. Statistical Methods in Medical Research 15 (4), 325-336.

Donaldson, A., Alexandersen, S., 2002. Predicting the spread of foot and mouth disease by airborne virus. Revue scientifique et technique (International Office of Epizootics) 21 (3), 569-575.

Düvel, G.H., Afful, D.B., 1996. Sociocultural constraints on sustainable cattle production in some communal areas of South Africa. Development Southern Africa 13 (3), 429-440.

Ferber, J., 1995. Les systèmes multi-agents. Vers une interlligence collective. InterEditions, Paris, 492 pp (In french).

Ferguson, N.M., Donnelly, C.A., Anderson, R.M., 2001. The foot-and-mouth epidemic in great britain: pattern of spread and impact of interventions. Science 292 (5519), 1155-1160.

Fostier, N. 2009. Détection des zones humides près du Parc Kruger (Afrique du Sud: Transfert d'échelle de la très haute à la haute résolution spatiale. Ms thesis, ULB.

Gainaru, M., Thomson, G., Bengis, R., Esterhuysen, J., Bruce, W., Pini, A., 1986. Foot and mouth disease and the African buffalo (Syncerus caffer). Onderstepoort Journal of Veterinary Research 53 (2), 75-85.

Gerbier, G., Bacrob, J., Pouillota, R., Duranda, B., Moutoua, F., Chadœuf, J., 2002. A point pattern model of the spread of food-and-mouth disease. Prentive Veterinary Medicine 56, 33-49.

Grimm, V., Revilla, E., Berger, U., Jeltsch, F., Mooij, W.M., Railsback, S.F., Thulke, H.-H., Weiner, J., Wiegand, T., DeAngelis, D.L., 2005. Pattern-oriented model- 
ing of agent-based complex systems: lessons from ecology. Science 310 (5750), 987-991.

Grimm, V., Berger, U., Bastiansen, F., Eliassen, S., Ginot, V., Giske, J., Goss-Custard, J., Grand, T., Heinz, S.K., Huse, G., Huth, A., Jepsen, J.U., Jorgensen, C., Mooij, W.M., Muller, B., Pe'er, G., Piou, C., Railsback, S.F., Robbins, A.M., Robbins, M.M., Rossmanith, E., Ruger, N., Strand, E., Souissi, S., Stillman, R.A., Vabo, R., Visser, U., DeAngelis, D.L., 2006. A standard protocol for describing individual-based and agent-based models. Ecological Modelling 198 (1-2), 115-126.

Halley, D.J., Mari, M., 2004. Dry season social affiliation of African buffalo bulls at the Chobe riverfront, Botswana. South African Journal of Wildlife Research 34 (2), 105-111.

Hijmans, R.J., Cameron, S., Parra J., 2005. WorldClim-Global Climate Data, http://www.worldclim.org/ (accessed February 2009).

Huffman, B., 2007. Ultimateungulate, http://www.ultimateungulate.com (accessed May 2008).

Jolles, A.E., 2007. Population biology of African buffalo (Syncerus caffer) at HluhluweiMfolozi Park, South Africa. African Journal of Ecology 45 (3), 398-406.

Jori, F., Vosloo, W., Du Plessis, B., Bengis, R., Brahmbhatt, D., Gummow, B., Thomson, G.R., 2009. A qualitative risk assessment of factors contributing to foot and mouth disease outbreaks in cattle along the western boundary of the Kruger National Park. Revue scientifique et technique (International Office of Epizootics) 28 (3), 917-931.

Keeling, M.J., Woolhouse, M.E.J., Shaw, D.J., Matthews, L., Chase-Topping, M., Haydon, D.T., Cornell, S.J., Kappey, J., Wilesmith, J., Grenfell, B.T., 2001. Dynamics of the 2001 UK foot and mouth epidemic: Stochastic dispersal in a heterogeneous landscape. Sciences 294 (5543), 813-818.

Kitching, R., 2005. Global epidemiology and prospects for control of foot-and-mouth disease. Current Topics in Microbiology and Immunology 288, 133-148.

Kitron, U., 1998. Landscape ecology and epidemiology of vector-borne diseases: tools for spatial analysis. Journal of Medical Entomology 35 (4), 435-445.

Kleijnen, J.P.C., 1995. Verification and validation of simulation models. European Journal of Operational Research 82 (1), 145-162.

Klein, J., 2009. Understanding the molecular epidemiology of foot-and-mouthdisease virus. Infection, Genetics and Evolution 9(2), 153-161.

Kock, R., 2005. What is this infamous "Wildlife/Livestock disease interface?" A review of current knowledge for the African continent. In: S. Osofsky (Ed.), IUCN Species Survival Commission report on Conservation and Development Interventions at the Wildlife/Livestock Interface Implications for Wildlife, Livestock and Human Health, pp. 1-14.

Kostova, T., Carlsen, T., Kercher, J., 2004. Individual-based spatially explicit model of an herbivore and its resource: the effect of habitat reduction and fragmentation. Comptes Rendus Biologies 327 (3), 261-276.

Lambin, E.F., Tran, A., Vanwambeke, S.O., Linard, C., Soti, V., 2010. Pathogenic landscapes: interactions between land, people, disease vectors, and their animal hosts. International Journal of Health Geographics 9, 54.

Law, A.M., 2008. How to build valid and credible simulation models. In: Proceedings of Winter Simulation Conference, pp. 39-47.

Lawson, A.B., Zhou, H., 2005. Spatial statistical modeling of disease outbreaks with particular reference to the UK foot and mouth disease (FMD) epidemic of 2001. Preventive Veterinary Medicine 71 (3-4), 141-156.

Linard, C., Ponçon, N., Fontenille, D., Lambin, E.F., 2009. A multi-agent simulation to assess the risk of malaria re-emergence in southern France. Ecological Modelling 220 (2), 160-174.

Morris, R., Wilesmith, J., Stern, M., Sanson, R., Stevenson, M., 2001. Predictive spatial modelling of alternative control strategies for the foot-and-mouth disease epidemic in Great Britain. The Veterinary Record 149, 137-144.

Ménard, B., 2002. Questions de géographie de la santé. Espace géographie 31 (3), 264-275.

Niazi, A.M., Hussain, A., Kolberg, M., 2009. Verification and validation of agent-based simulation using the VOMAS approach. In: Proceedings of the Third Workshop on Multi-Agent Systems and Simulation' 09 , Torino, Italy.

Ostfeld, R.S., Glass, G.E., Keesing, F., 2005. Spatial epidemiology: an emerging (or re-emerging) discipline. Trends in Ecology und Evolution 20 (6), 328-336.

Parrott, L., 2009. Understanding and managing the landscape as a complex system: what can bottom-up modelling approaches contribute? In: Proceedings of the Place and Purpose Symposium , 15 pp.

Perez, L., Dragicevic, S., 2009. An agent-based approach for modeling dynamics of contagious disease spread. International Journal of Health Geographics 8 (1), 50.

Pienaar, U., 1969. Obsevations on developmental biology, growth and some aspects of the population ecology of African buffalo (Syncerus caffer caffer, Sparrman). Koedoe 12, 29-52.

Plackett, R.L., Burman, J.P., 1946. The design of optimum multifactorial experiments. Biometrika 33 (June (4)), 305-325.
Rivas, A.L., Schwager, S.J., Smith, S., Magri, A., 2004. Early and cost-effective identification of high risk/priority control areas in foot-and-mouth disease epidemics. Journal of Veterinary Medicine Series B-Infectious Diseases and Veterinary Public Health 51 (6), 263-271.

Roche, B., Guegan, J., Bousquet, F., 2008. Multi-agent systems in epidemiology: a first step for computational biology in the study of vector-borne disease transmission. BMC Bioinformatics 9 (1), 435.

Rodwell, T.C., Kriek, N.P., Bengis, R.G., Whyte, I.J., Viljoen, P.C., De Vos, V., Boyce, W.M., 2001. Prevalence of bobine turberculosis in african buffalo at Kruger National Park. Journal of Wildlife Diseases 37 (2), 258-264.

Ryan, S., Jordaan, W., 2005. Activity patterns of African buffaloe Syncerus caffer in the lower Sabie Region, Kruger National Park, South Africa. Koedoe 48 (2), 117-124

Ryan, S.J., Knechtel, C.U., Getz, W.M., 2006. Range and habitat selection of African buffalo in South Africa. Journal of Wildlife Management 70 (3), 764-776.

Sargent, R.G., 2009. Validation and verification of simulation models. In: Proceedings of the 42nd Conference on Winter Simulation , pp. 162-176.

South African National Parks, 2001-2007. SANParks, http://www.sanparks.org/. SANparks database, Fence breaks, CyberTrackerProgram, 2005-2007. SANparks, 2007. Hotspots of buffaloes, http://celtis.sanparks.org/parks/kruger/sightings/ 2007/quarterly_hotspots/default.php (accessed April 2008).

Sinclair, A.R.E., 1977. The African Buffalo: a study of resource limitation of populations. The University of Chicago Press, Chicago, 355 pp.

Sutmoller, P., Thomson, G.R., Hargreaves, S.K., Foggin, C.M., Anderson, E.C., 2000 The foot-and-mouth disease risk posed by African buffalo within wildlife conservancies to the cattle industry of Zimbabwe. Preventive Veterinary Medicine $44(1-2), 43-60$.

Sutmoller, P., 2002. The fencing issue relative to the control of foot-and-mouth disease. Animal Health Consultant 969, 191-200.

Sutmoller, P., Barteling, S.S., Olascoaga, R.C., Sumption, K.J., 2003. Control and eradication of foot-and-mouth disease. Virus Research 91 (1), 101-144.

Swinnen, E., Veroustraete, F., 2008. Extending the SPOT-VEGETATION time series (1998-2005) back in time with NOAA-AVHRR data (1985-1998) for Southern Africa. IEEE Transactions on Geoscience and Femote Sensing 46 (2), 558-572.

Taylor, R.D., Martin, R.B., 1987. Effects of veterinary fences on Wildlife conservation in Zimbabwe. Environmental Management 11 (3), 327-334.

Thompson, M.W., 1996. Standard land cover classification scheme for remote sensing applications in South Africa. South African Journal of Science 92 (1), 34-42.

Thomson, G.R., 1996. The role of carrier animals in the transmission of foot-andmouth disease. Office International des Epizooties. Comprehensive Reports on Technical Items Presented to the International Committee or to Regional Commissions, pp. 87-103.

Thomson, G.R., Vosloo, W., Bastos, A.D.S., 2003a. Foot and mouth disease in wildlife Virus Research 91 (1), 145-161.

Thomson, G.R., Vosloo, W., Bastos, A., 2003b. The epidemiology and control of footand-mouth disease in sub-saharian Africa. Foot-and-mouth disease: control strategies. In: Dodet, B., Vicari, M. (Eds.), Proceedings of International Symposium on Foot-and-Mouth Disease. 2-5 June 2002, Lyon, France. Éditions scientifiques et médicales, Elsevier SAS, pp. 125-134.

Thomson, G.R., Bastos, A., 2004. Foot-and-mouth disease. In: Coetzer, J.A.W., Tustin, R.C. (Eds.), Infectious Diseases of Livestock. Oxford University Press, Cape Town, pp. 1324-1365.

Thomson, G.R., 2008. A short overview of regional positions on foot-and-mouth disease control in southern Africa. Brighton. Disease in sub-saharian Africa. In: Dodet, B., Vicari, M. (Eds.), Foot-and-Mouth Disease: Control Strategies. , pp. $125-134$.

Vosloo, W., Bastos, A.D., Kirkbride, E., Esterhuysen, J.J., van Rensburg, D.J., Bengis, R.G., Keet, D.W., Thomson, G.R., 1996. Persistent infection of African buffalo (Syncerus caffer) with SAT-type foot-and-mouth disease viruses: rate of fixation of mutations, antigenic change and interspecies transmission. Journal of General Virology 77 (7), 1457-1467.

Vosloo, W., Bastos, A., Sangare, O., Hargreaves, S., Thomson, G., 2002. Review of the status and control of foot and mouth disease in sub-Saharan Africa. Revue scientifique et technique (International Office of Epizootics) 21 (3), 437-439.

Vosloo, W., de Klerk, L., Boshoff, C., Botha, B., Dwarka, R., Keet, D., Haydon, D., 2007. Characterisation of a SAT-1 outbreak of foot-and-mouth disease in captive African buffalo (Syncerus caffer): clinical symptoms, genetic characterisation and phylogenitic comparison of outbreak isolates. Veterinary Microbiology 120 (3-4), 437-449.

Wilensky, U., 1999. NetLogo i4.0 User Manual, http://ccl.northwestern.edu/netlogo/

Winterbach, H.E.K., Bothma, J.D.P., 1998. Activity patterns of the Cape buffalo Syncerus caffer caffer in the Willem Pretorius Game Reserve, Free State. South African Journal of Wildlife Research 28 (3), 73.

Wu, C.F.F., Hamada, M., 2000. Experiments, Planning, Analysis and Parameter Design Optimization. John Wiley and Sons, New York. 